\title{
Effects of Local Biomass Availability and Road Network Properties on the Greenhouse Gas Emissions of Biomass Supply Chain
}

\author{
E. Jäppinen, O.-J. Korpinen, and T. Ranta \\ Lappeenranta University of Technology, Prikaatinkatu 3 E, 50100 Mikkeli, Finland \\ Correspondence should be addressed to E. Jäppinen, eero.jappinen@lut.fi \\ Received 1 August 2011; Accepted 17 August 2011 \\ Academic Editors: K. Kaygusuz and S. Kim
}

Copyright (C) 2011 E. Jäppinen et al. This is an open access article distributed under the Creative Commons Attribution License, which permits unrestricted use, distribution, and reproduction in any medium, provided the original work is properly cited.

\begin{abstract}
This study presents two case studies of 100 GWh of forest biomass supply: Rovaniemi in northern Finland and Mikkeli in southeastern Finland. The study evaluates the effects of local biomass availability and road network properties on the greenhouse gas (GHG) emissions of these two supply chains. The local forest biomass availability around the case study locations, truck transportation distances, and road network properties were analyzed by GIS methods to produce accurate and site-dependent data for the transportation emission calculations. The GHG emissions were then assessed by LCA methods. The total transportation distance to Rovaniemi was $22 \%$ larger than to Mikkeli, but the transportation derived GHG emissions were $31 \%$ larger. The results highlight the fact that local conditions should always be taken into account when assessing the sustainability of biomass-based energy production.
\end{abstract}

\section{Introduction}

The sustainability of biomass production for energy purposes is dependent on many factors. These include, for example, land use change and its further consequences, possible changes in the carbon stocks of the soil, changes in the biomass production capacity of the area in question, energy consumption of the biomass supply chain, and the efficiency of converting the biomass to the desired energy carriers or heat or electricity. One thing that significantly affects the energy consumption and emissions of the biomass supply chain is the local availability of suitable biomass. It is common sense that production facilities that utilize a certain bulk raw material, such as biomass, should be located near or in the middle of the raw material sources to avoid unnecessary transportation of unrefined and cheap material. The practical availability and supply chain emissions however depend also very much on the local transportation possibilities of raw material in question.

In case of forest-based biomass, such as chipped forest residues or small diameter energy wood, the first step of the transportation chain is almost always truck transportation. Normally, when transportation distances are under $100 \mathrm{~km}$ or so, the only method is truck transportation, as the costs of unloading and reloading the cargo would be higher than the possible savings achieved through transportation by train or ship [1]. In many cases truck transportation is in fact the only viable option. Thus, the road network properties play a significant role in the formation of transportation costs and transport-related emissions. In other words, the actual and practical availability of biomass to the end user and the supply chain emissions is a function of local biomass availability and the local transportation possibilities.

The European Union recommends its member states to implement sustainability criteria on biomass production for energy purposes in their national legislation. The national criteria should require a $35 \%$ reduction of greenhouse gases emitted from biomass-based energy production when compared to EU's fossil energy mix. The GHG saving requirements for biomass utilizing new installations should eventually rise up to $60 \%$ in 2018 [2]. The calculation of these savings is however far from simple. According to the EU 
Renewable Energy Directive, the greenhouse gas emissions from the production and use of transport fuels, biofuels, and bioliquids will be calculated as [2]

$$
E=\mathrm{eec}+\mathrm{el}+\mathrm{ep}+\mathrm{etd}+\mathrm{eu}-\mathrm{esca}-\mathrm{eccs}-\mathrm{eccr}-\mathrm{eee},
$$

where $E$ : total emissions from the use of the fuel; eec: emissions from the extraction or cultivation of raw materials; el: annualised emissions from carbon stock changes caused by land-use change; ep: emissions from processing; etd: emissions from transport and distribution; eu: emissions from the fuel in use; esca: emission saving from soil carbon accumulation via improved agricultural management; eccs: emission saving from carbon capture and geological storage; eccr: emission saving from carbon capture and replacement; eee: emission saving from excess electricity from cogeneration.

The Renewable Energy Directive also states that the emissions from transport and distribution will include emissions from the transport and storage of raw and semifinished materials and from the storage and distribution of finished materials. It does not however give any instructions or more strictly defined guidelines on how these transportation emissions should be calculated. Often in studies concerning biomass energy use, the transportation distances and transportation-derived emissions are based on estimated average distances and collection areas [3-5].

When the same type of biomass from similarly managed sources is used and the biomass is similarly collected and processed to be utilised as energy, the largest differences in supply chain emissions come from the transportation activities. Transportation emissions rely on several factors, including, for example, choice of transportation method (road, railway and waterway, and their combinations), type of transportation equipment that is used (e.g., specific large volume trucks for forest fuels may be used), emission characteristics of the equipment that is used, load weight restrictions that may lead to inefficient use of cargo space, used motor fuels or origin of electricity, weather conditions and properties of the transportation network.

The purpose of this study was to assess this difference between two cases in Finland that utilise the same amount of the same raw material, $100 \mathrm{GWh} / \mathrm{a}$ of small diameter energy wood. Even though forest-based biomass from adequately managed forests in Finland should easily fulfill today's sustainability criteria [6], mainly because there is no large fertilization needs or land-use changes involved, there still are differences in emissions due to local availability and transportation activities.

The assessment of actual local conditions and supply chain emissions may become increasingly important in the future, if the sustainability requirements for biomass become stricter. Also, the same raw material, for example, forest residue or small diameter energy wood chips produced in Finland, can be utilised locally or transported longer distances by truck, train, or waterway transportation, resulting in different supply chain emissions. Thus, an emission figure representing national or regional averages, for example, forest chips made in EU as in [6], does not represent the actual emissions in most cases. Also, the use of average emission figures does not necessarily drive the actors in the biomass supply field to develop their processes and perform better in terms of emissions and energy efficiency.

The quality and accuracy of a life cycle assessment is dependent on the input data. By utilising locationand case-dependent biomass availability and transportation emission data, the accuracy of sustainability assessments will be significantly improved. The same method of using geographical information systems (GIS) based local raw material availability assessment and transportation network analysis as basis for emission calculations or LCA studies can also be used in other applications besides biomass supply studies. Basically any supply chain where the transported material is spread around a larger geographical area could be assessed using the same methods, for example, waste collection activities.

\section{Material and Methods}

2.1. Calculation Procedure. The assessment of emissions deriving from biomass transportation was based on a threestep procedure: biomass availability assessment, analysis of transportation network properties, and emission calculations.

2.2. Biomass Availability Assessment. First, the availability of biomass needed to be accurately assessed, taking into account the scale of biomass supply. For smaller supply areas, such as in the two cases of this study where driving distances are under $100 \mathrm{~km}$, the local availability needs to be taken into account on a detailed level in order to obtain site-specific results and reveal the possible differences due to location. For very large supply areas covering hundreds of kilometers, the local differences in biomass availability tend to level out, and the accuracy of biomass availability data in terms of exact geographical location does not have to be as accurate as when studying local scale supply chains.

In this study the geographical reference area, Finland, was divided into a geographical $2 \mathrm{~km} \times 2 \mathrm{~km}$ grid. The midpoints of each square of the grid were then given a figure which represents the share of productive forest land within each square with a total area of $4 \mathrm{~km}^{2}$, see Figure 1 .

For each $4 \mathrm{~km}^{2}$ square the share of biomass producing forest area was calculated by means of raster analysis with GRASS GIS software. The forest area that was taken into account in this study was forest land in the growth categories of forestry land in [7]. Forest land is defined by the Finnish Forest Research Institute as land area where the average growth of forest is $>1 \mathrm{~m}^{3} /$ year/ha. This method enables the exclusion of unsuitable land areas that do not produce biomass for this specific purpose from the calculations. These unsuitable areas include, for example, areas covered with water, urban areas, roads, fields, and also forest areas with poorer growing conditions. The land use categories are based on the SLICES land use data with $10 \mathrm{~m} \times 10 \mathrm{~m}$ raster density [8]. Also, as whole Finland was divided into the $4 \mathrm{~km}^{2}$ squares, some middle points of these squares did not fall on Finnish territory, or they were totally offshore. These points were deleted out from the grid. 


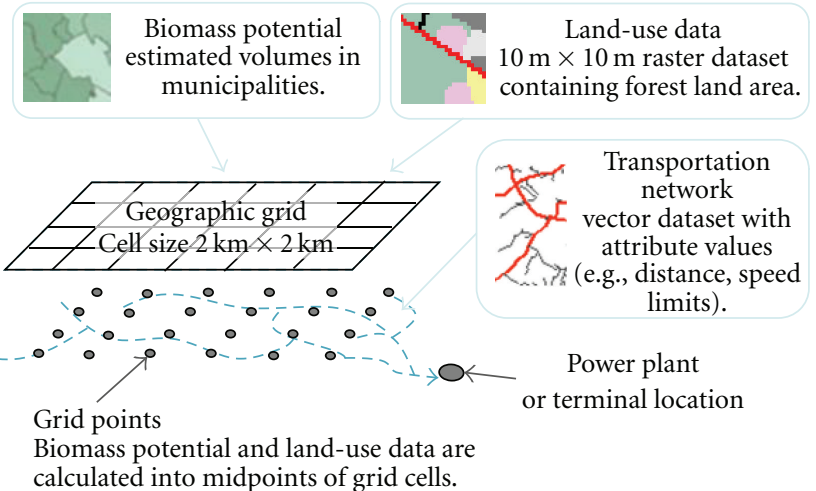

FIGURE 1: Biomass supply point grid system.

The availability estimations of biomass for each point in the grid were based on the national forest inventory data produced by Finnish Forest Research Institute in $2008[9,10]$. The data provides an energy wood potential figure representing the technically feasible amount of small diameter energy wood that could be harvested annually from each of the 399 municipalities in continental Finland without negatively affecting the future growth of the forests. The total municipal energy wood potential figure was then allocated to the $2 \mathrm{~km} \times 2 \mathrm{~km}$ grid midpoints according to the productive forest land area within each square. The technical potential of small diameter energy wood does not, however, represent the practical potential that is available for energy production purposes at an economically feasible price, that is, techno-economical potential. The technoeconomical energy wood potential is less than the technical potential due to, for example, the following factors: lack of information about suitable harvestable stands, too high harvesting and transportation costs due to a remote location and lack of subsidies that are often required to achieve economic harvesting and collection of small diameter energy wood. The techno-economical potential can be estimated to be ca. $50 \%$ of the technical maximum potential $[11,12]$ The theoretical technical potential for each supply point in this study was therefore adjusted by a factor of 0.5 , representing the estimated share of biomass that the plants of this study could be able to procure around their locations. There are also other limitations to the availability of small diameter energy wood, such as competition over the same resources and some forest owners unwillingness to sell. These additional possible limitations are not taken into account in this study, and the $50 \%$ techno-economical share of the theoretical technical potential is considered to be the same for both case study locations of this study.

The heating value that was used in the calculations was $2.12 \mathrm{MWh} / \mathrm{m}_{\text {solid }}^{3}$, representing a typical value for small diameter energy wood chips with ca. 36\% moisture content. The density of wood was $420 \mathrm{~kg} / \mathrm{m}_{\text {solid, dry matter [13], and the }}^{3}$ total weight of $100 \mathrm{GWh}$ of chips with $36 \%$ moisture content to be transported was $30953000 \mathrm{~kg}$.

2.3. Transportation Network Analysis. Secondly, after the biomass availability was assessed and the geographical locations of supply points and their biomass resources were in place, the information had to be linked to the transportation methods and transportation network that will be utilized. This requires accurate and site-specific information on transportation networks. In the two cases of this study, only road transportation by trucks was analyzed. Truck transportation is the dominating method in regional scale supply of biomass in Finland. In larger scale supply chains when the supply area is significantly larger also train and waterway transportation can be used where suitable conditions exist. The aim of this study was however only to evaluate the effects of differences in local availability of biomass and road network properties in the total transportation-derived emissions, and not to optimize or analyze different combinations of transportation methods.

In the two cases of this study, when the amount of biomass is only $100 \mathrm{GWh} / \mathrm{a}$, the transportation would also in practice be done solely by truck. The supply points, that is, the midpoints of the $2 \mathrm{~km} \times 2 \mathrm{~km}$ grid were linked directly to the nearest road. The longest road transportation distances to single supply points needed to supply the $100 \mathrm{GWh}$ of biomass to the demand points were $45 \mathrm{~km}$ in Mikkeli and $54 \mathrm{~km}$ in Rovaniemi, which represented the maximum driving radius' along the road network around the demand points. The supply points which were located inside the $45 \mathrm{~km}$ and $54 \mathrm{~km}$ driving radius' in Mikkeli and Rovaniemi, respectively, but more than $1 \mathrm{~km}$ from the nearest road, were excluded from the calculations due to the fact that they probably would not be economically viable for energy use due to increasing forest transportation, that is, forwarding costs. This selection criteria ruled out $1 \%$ of the supply points in Mikkeli ( 6 out 968 supply points) and 9\% (114 out of 1247 supply points) in Rovaniemi.

The distances traveled on each road type to transport the desired $100 \mathrm{GWh}$ of biomass to the demand points were calculated with ArcGIS software. The road properties were acquired from the national road and street database of Finland, Digiroad [14]. The routes for each truckload of biomass from the supply points to the endpoints (a powerplant location in both cases) were optimized with a route planning GIS application to be as short as possible.

In real forest biomass transportations, the truck routes would be planned so that a truck would pick up the remainings of one roadside storage and then move on to the next one to achieve a full truckload whenever suitable roadside storages would be situated near each other. This is however not always possible or economical, and in some cases, the trucks have to drive with only a partial load to the plant. In this study the driving distances and emissions were adjusted by a factor so that, for example, for a $50 \%$ full truck load only $50 \%$ of the distance and emissions were accounted for. This was done because the truck routes were calculated directly from the supply points to the plants without taking into account the possibility to visit multiple storages during the same trip. For example, if a supply point had enough biomass to fill 1.5 truckloads, the distances and emissions were multiplied by a factor of 1.5 . This results in the calculated total driving distances and transportation-related emissions to be slightly less than what they would be in real life, because the partially full truckloads are assumed to be 
driven only partial distances. This is however compensated by the fact that the driving routes from each supply point are optimized to be as short as possible. Also, whenever multiple stops at supply points are arranged to achieve full truckloads, the driving distances become longer.

The roads that were used were categorized into three different road types from the Digiroad road classification: small roads (forest roads and roads within a city, average speed $27 \mathrm{~km} / \mathrm{h}$ ), regional roads (paved roads, average speed $70 \mathrm{~km} / \mathrm{h}$ ), and motorway (large paved roads, average speed $82 \mathrm{~km} / \mathrm{h}$ ). The road classification from the Digiroad classes into these three categories was done according to the maximum allowed speed for each road segment. Roads with speed limits of $50 \mathrm{~km} / \mathrm{h}$ or under were classified as small roads, over $50 \mathrm{~km} / \mathrm{h}$ but under $80 \mathrm{~km} / \mathrm{h}$ were classified as regional roads, and roads with a speed limit of $80 \mathrm{~km} / \mathrm{h}$ or higher were classified as motorways. The classification into these three categories was done because the LCA dataset [15] that was used to assess the truck transportation emissions uses this three-level classification in the LCA unit process emission calculation. Driving on smaller roads (e.g., typical unpaved gravel forest roads) consumes more fuel and results in more emissions per distance than driving on larger paved roads.

In this study, whenever a biomass supply point was needed to obtain the desired amount of biomass to the plant, all biomass from the same supply point was considered to be collected at once. This lead to the situation that the total amount of biomass collected was not exactly $100 \mathrm{GWh}$, but it was 99.0 GWh and 98.1 GWh for Mikkeli and Rovaniemi, respectively. To obtain an exact amount of $100 \mathrm{GWh}$ of biomass for the transportation and emission calculations, these amounts were adjusted to be $100 \mathrm{GWh}$ by a correcting factor. The correcting factor was obtained by calculating a $\mathrm{km} / \mathrm{MWh}$ figure for all three road types for both case studies, and then multiplying that figure to obtain the kilometers that were driven on each road type to supply the $100 \mathrm{GWh}$ of biomass to the plants.

2.4. Emission Calculations. The emissions from the transportation activities were calculated with GaBi professional LCA software. The truck type used for the calculations was a 34-40 ton total capacity, 27 ton payload Euro 4 emission level truck [15], representing the largest truck type allowed on European roads [16]. Although larger trucks with maximum total capacity of 60 tons can be used, and are mostly used, in Finland for forest biomass transportations, due to a national exemption to the EEC directive in Finland [17], the smaller European $40 \mathrm{t}$ truck type was used in the calculations of this study in order to facilitate further comparisons between emissions deriving from biomass supply and transportation in other countries besides Finland as well (and Sweden, where larger $60 \mathrm{t}$ trucks can also be used). A 40 ton truck has an average maximum bulk cargo capacity of $96 \mathrm{~m}^{3}$, as opposed to $110 \mathrm{~m}^{3}$ bulk cargo capacity of a 60 ton truck [18]. A $96 \mathrm{~m}^{3}$ load of woodchips with $36 \%$ moisture results in a payload of 25.2 tons, which is still within the limits of maximum total weight for the $40 \mathrm{t}$ truck, as the average tare weight of a $40 \mathrm{t}$ truck is ca. 14 tonnes. Similarly, a $110 \mathrm{~m}^{3}$ woodchip load would weigh ca. 28.9 tonnes. Thus, the use of smaller 40 ton trucks as basis for the emission calculations in this study resulted in larger emission figures than with larger 60 ton trucks, because the smaller bulk cargo volume necessitates more driving. The total driving distance needed to supply $100 \mathrm{GWh}$ of woodchips with a 40 ton truck was $15 \%$ larger than with a $60 \mathrm{t}$ truck $\left(110 \mathrm{~m}^{3}\right.$ cargo is $15 \%$ larger than a $96 \mathrm{~m}^{3}$ cargo). Although the total driven distance and the emissions per ton of cargo transported for a certain distance increase when using smaller trucks, the larger and heavier trucks would cause more emissions per kilometer driven when fully loaded. This compensates the difference in emissions to be lower than $15 \%$, which is the difference in load size.

However, the focus of this study was to assess the possible differences in transportation-derived emissions that are due to road properties and local biomass availability around the plants, and not to calculate exact equipment-specific emission figures for the truck transportations.

The emissions calculation for diesel oil production and supply was based on an LCA dataset for diesel oil at refinery in EU-15 countries [15]. The emission calculations do not include diesel fuel transportations to the places of distribution where trucks fill up their tanks. The climate change potential of the GHG emissions was assessed by using CML 2001 methodology with 100 year time perspective [19], and the results are given in $\mathrm{CO}_{2}$-equivalents.

Forwarding the biomass to the roadside from within the forest was excluded from the calculations as well as the chipping of wood. Also, the building of roads and other infrastructure and manufacturing of the trucks and other transportation-related equipment were excluded from emission calculations. Only emissions of truck transportation due to fuel consumption and lubrication and emissions deriving from the production and supply of the diesel oil used in the trucks were included in the assessment. The emission calculations included empty returns of the trucks.

2.5. Case Studies. This work included two case studies with the same annual demand of the same type of forest-based biomass: $100 \mathrm{GWh}$ of forest chips made from small diameter energy wood. The transportation endpoint locations were Rovaniemi, located in northern Finland just south of the arctic circle (latitude: $66^{\circ} 30^{\prime} 0^{\prime \prime} \mathrm{N}$ ), and Mikkeli, located in south-eastern Finland $\left(61^{\circ} 41^{\prime} 0^{\prime \prime} \mathrm{N}\right)$, see Figure 2.

There is a large woody biomass utilizing powerplant in Mikkeli, and a large biomass powerplant is under planning phase to be built in Rovaniemi, so both cases represented realistic scenarios of biomass supply.

Small diameter energy wood was chosen for this supply study, because it is the forest biomass fraction that has the largest potential for growing use in the future in Finland [12]. Generally, out of the three basic forest biomass fractions, which are logging residues, tree stumps, and small diameter energy wood, logging residues are the cheapest fraction, followed by stumps. The economically best sites for logging residue collection and stump harvesting are however already so widely utilized in Finland, that the largest potential lies in the more expensive small diameter energy wood [9]. 


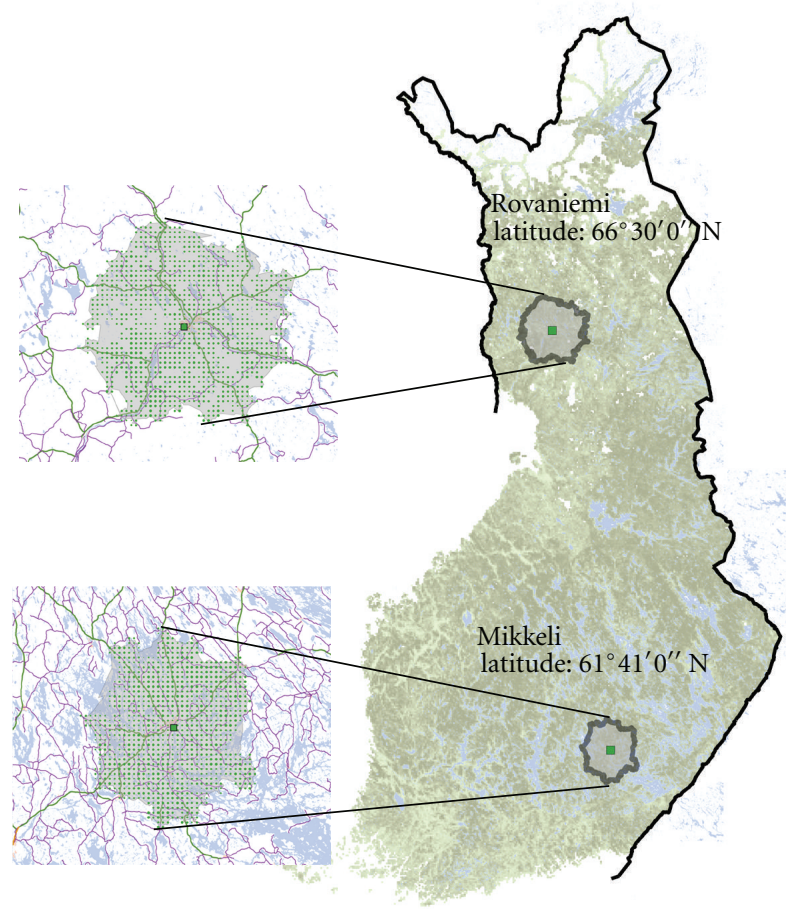

FIGURE 2: Case study locations and their supply areas.

\section{Results}

The transportation distances per road type needed to supply of $100 \mathrm{GWh}$ of small diameter energy wood chips to the two case study locations are presented in Figure 3.

The total truck transportation distance was ca. $74700 \mathrm{~km}$ to Mikkeli and ca. $90800 \mathrm{~km}$ to Rovaniemi. The total distance was 22\% larger in Rovaniemi case. The average driving distance from a supply point to the endpoint was $67 \mathrm{~km}$ in Mikkeli and $71 \mathrm{~km}$ in Rovaniemi.

The transportation-induced GHG emissions are presented in Figure 4.

The transportation of $100 \mathrm{GWh}$ of wood chips made of small diameter energy wood produced 154 and 202 tons of $\mathrm{CO}_{2-\text { eq. }}$ to Mikkeli and Rovaniemi, respectively. The transportation derived emissions were 31\% larger for Rovaniemi, even though the total driving distance was only $22 \%$ larger. This resulted from the fact that the quality of roads and density of road network around Rovaniemi region is poorer than around Mikkeli. To transport $100 \mathrm{GWh}$ of small diameter energy wood chips to Rovaniemi from the surrounding areas, a distance of $30600 \mathrm{~km}$ needs to be driven on small roads, which are mainly gravel forest roads. In Mikkeli's case, the distance covered on small roads is only $14300 \mathrm{~km}$.

\section{Discussion}

This study assessed the emissions deriving from truck transportation of $100 \mathrm{GWh}$ of wood chips made of small diameter energy wood from the surrounding forest areas to two different demand points in Finland. The other demand

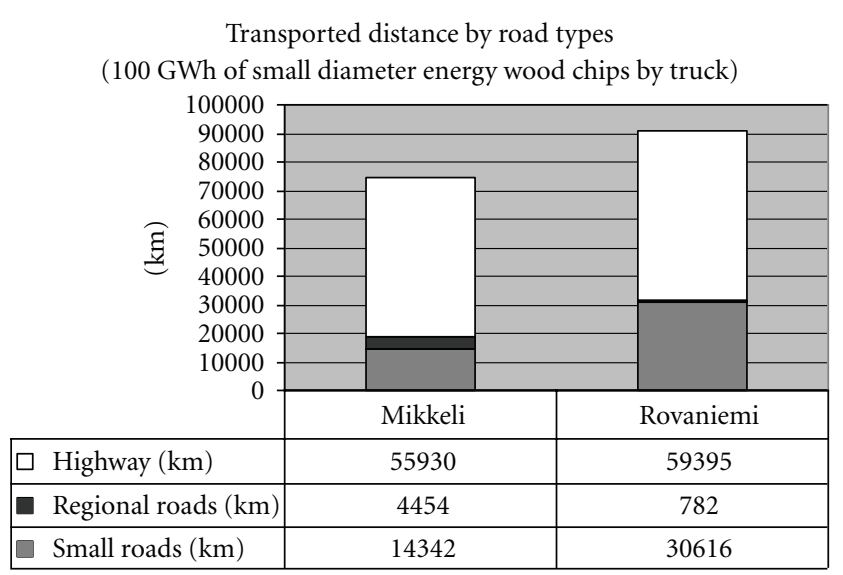

Figure 3: Total transported distances to the two case study locations.

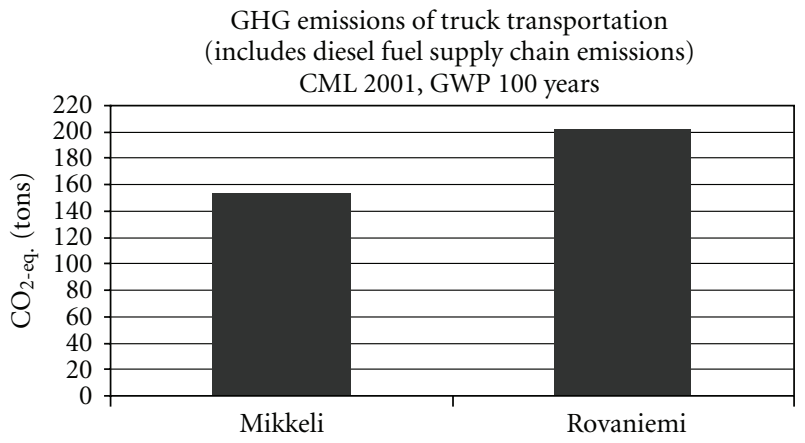

FIGURE 4: Transportation-derived GHG emissions.

point was Rovaniemi in northern Finland near the polar circle (latitude: $\left.66^{\circ} 30^{\prime} 0^{\prime \prime} \mathrm{N}\right)$, and the other was Mikkeli in south-eastern Finland $\left(61^{\circ} 41^{\prime} 0^{\prime \prime} \mathrm{N}\right)$. The main purpose of this study was to evaluate and demonstrate the possible differences in GHG emissions of biomass supply chains that are caused by local conditions in biomass availability and road network.

The two case studies of this work were quite similar, both used the same raw material and same transportation methods; the supply areas were located around the plants, and the case locations were only ca. $550 \mathrm{~km}$ apart. The only differences were that in northern Finland (Rovaniemi case) the forests are not as dense, and the road network is poorer. The total driving distance to Rovaniemi was only $22 \%$ longer, but the GHG emissions from transportation were 31\% larger. This was due to the fact that the share of driving on small roads, which consumes more fuel, was 34\% in Rovaniemi's case in comparison to $19 \%$ in Mikkeli's case. This shows that whenever the sustainability of a biomass production chain is assessed, the local conditions should be taken into account as accurately as possible, including the properties of the transportation network that is used.

One can not make accurate comparisons of biomass supply chains' emissions by relying on average transportation distances or biomass availability figures. The same kind of biomass-based end products (e.g., electricity, heat, 
or biodiesel) may have significantly different total GHG emissions deriving from the production chain because the production facilities are in different locations and the local conditions are different. A case study made by Metsäteho Oy [20] about feedstock supply chain GHG emissions in Finland evaluated the share of truck transportation's emissions in the total emissions of forest biomass supply for liquid biofuel production. For a supply chain based on small sized thinning wood chipped at the roadside landing, which is a similar supply chain as in this study, the truck transportation's share of total emissions was estimated to be $16 \%$. The study included supply chain operations starting from the wood production in the forest and ending in chips delivered at the plant (wood production, cutting of trees, forwarding, transportation of machines and labor force, chipping and truck transportation). The study included also logging residues and stumps for a total of $1 \mathrm{mill} \cdot \mathrm{m}_{\text {solid }}^{3}$ biomass delivered to the plant, of which $5 \%$ in volume was smallsized thinning wood. The amount of small-sized thinning wood $\left(5 \%\right.$ of $\left.1 \mathrm{mill} \cdot \mathrm{m}_{\text {solid }}^{3}\right)$ equals ca. $106 \mathrm{GWh}$ in energy content, which is in the same range as the supply of this study. Thus, it can be roughly estimated that for a full-supply chain including all other operations in addition to truck transportation as well as the difference in total emissions due to biomass availability and local road network properties would be around 5\% for the two cases of this particular study. As previously stated, the two cases of this study were quite similar, and further research is needed to evaluate the differences for supply chains of different raw materials, with different scales and geographical locations and with other transportation alternatives as well.

The differences in supply chains' emissions lead to the question that how should these differences in sustainability be taken into account in decision making concerning renewable energy production from biomass? Should the same end product be treated as less sustainable, if it is produced in a location where the local conditions are worse?

These location- and case-dependent sustainability issues are likely to become an increasingly discussed topic as international biomass trading grows, forest biomass procurement from further supply areas to, for example, central Europe increases, and competition for the same biomass sources grows.

\section{References}

[1] K. Karttunen et al., "Inland waterway transport of forest fuels," Research Report, Lappeenranta University of Technology, 2008.

[2] Directive 2009/28/EC of the European Parliament and of the Council of 23 April 2009 on the promotion of the use of energy from renewable sources and amending and subsequently repealing Directives 2001/77/EC and 2003/30/EC.

[3] J. Leboreiro and A. K. Hilaly, "Biomass transportation model and optimum plant size for the production of ethanol," Bioresource Technology, vol. 102, no. 3, pp. 2712-2723, 2011.

[4] P. Börjesson and L. Gustavsson, "Regional production and utilization of biomass in Sweden," Energy, vol. 21, no. 9, pp. 747-764, 1996.
[5] P. I. I. Börjesson, "Emissions of CO2 from biomass production and transportation in agriculture and forestry," Energy Conversion and Management, vol. 37, no. 6-8, pp. 1235-1240, 1996.

[6] European Commission, Report from the Commission to the Council and the European Parliament on sustainability requirements for the use of solid and gaseous biomass sources in electricity, heating and cooling, 2010, http://ec.europa .eu/energy/renewables/transparency_platform/doc/2010_report/com_2010_0011_3_report.pdf.

[7] Finnish Forest Research institute, http://www.forest.fi/smyforest/foresteng.nsf/allbyid/4C9E037BF9291D76C22572BF00471CD0?Opendocument\#Untitled\%20Section_0.

[8] SLICES Database. National Land Survey of Finland, 2006, http://www.paikkatietohakemisto.fi/geonetwork/srv/fi/main .home?id=269.

[9] J. Hynynen, "Bioenergiaa metsästä -metsiemme bioenergiavarat ja energiapuun talteenoton vaikutukset," Finnish Forest Research Institute, Presentation in Energiapuussa tulevaisuus-conference, 2008.

[10] J. Laitila, A. Asikainen, and P. Anttila, "1. Energiapuuvarat," in Energiapuun Korjuun Ympäristövaikutukset, Tutkimusraportti, M. Kuusinen and H. Ilvesniemi, Eds., pp. 6-12, Forestry Development Centre Tapio and Finnish Forest Research Institute, 2008.

[11] J. Laurila et al., "Metsäenergiapotentiaali ja energiapuun korjuun resurssitarpeet Etelä-Pohjanmaan metsäkeskuksen alueella," Metsätieteen Aikakauskirja, vol. 4, pp. 355-365, 2010.

[12] M. Maidell et al., "Regional potentials for forest-based energy in Finland," Pellervo Economic Research Institute, Working Papers No. 106. P. 42, 2008.

[13] K. Karttunen et al., "Energy wood from South-Savo," Faculty of Technology, LUT Energy, Research Report 7, 2010.

[14] Digiroad, Finnish Transport Agency, 2010, http://www .digiroad.fi/dokumentit/en_GB/documents/.

[15] GaBi Databases, 2006.

[16] Directive 96/53/EEC, OJ L.235, 1996, http://eurlex.europa .eu/LexUriServ/LexUriServ.do?uri=CELEX:31996L0053:EN :HTML.

[17] Decree on the use of vehicles on the road (1257/1992), Ministry of Transport and Communications of Finland.

[18] H. Backman and R. Nordström, Improved Performance of European Long Haulage Transport, report nr. 6E, TFK Transport Research Institute, 2002.

[19] J. B. Guinée et al., LCA An operational guide to the ISOstandards. Part 1: LCA in perspective, Final Report, 2001.

[20] A. Kariniemi et al., Feedstock Supply Chain CO2-eq Emissions-A Case Study on Forest Biomass for 2nd Generation Liquid Traffic Fuel, Metsäteho Oy, 2009. 

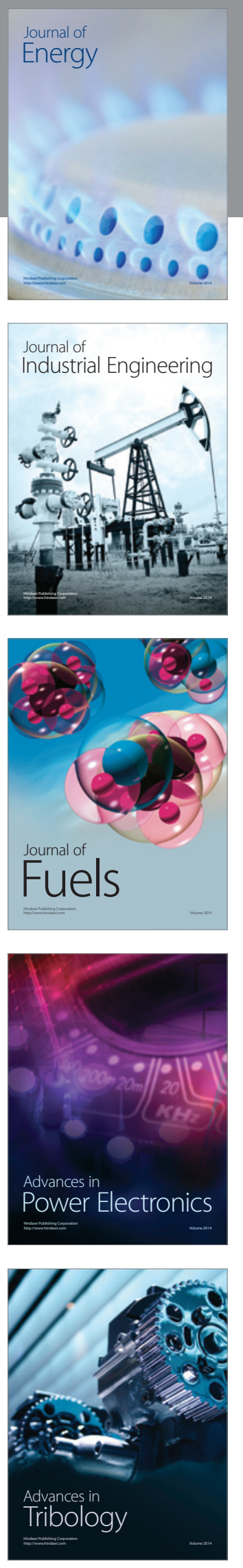
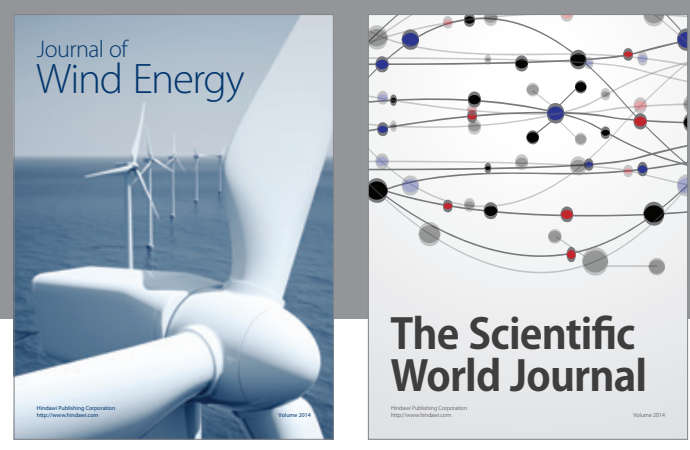

The Scientific World Journal

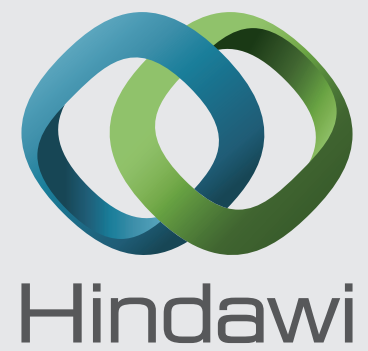

Submit your manuscripts at http://www.hindawi.com
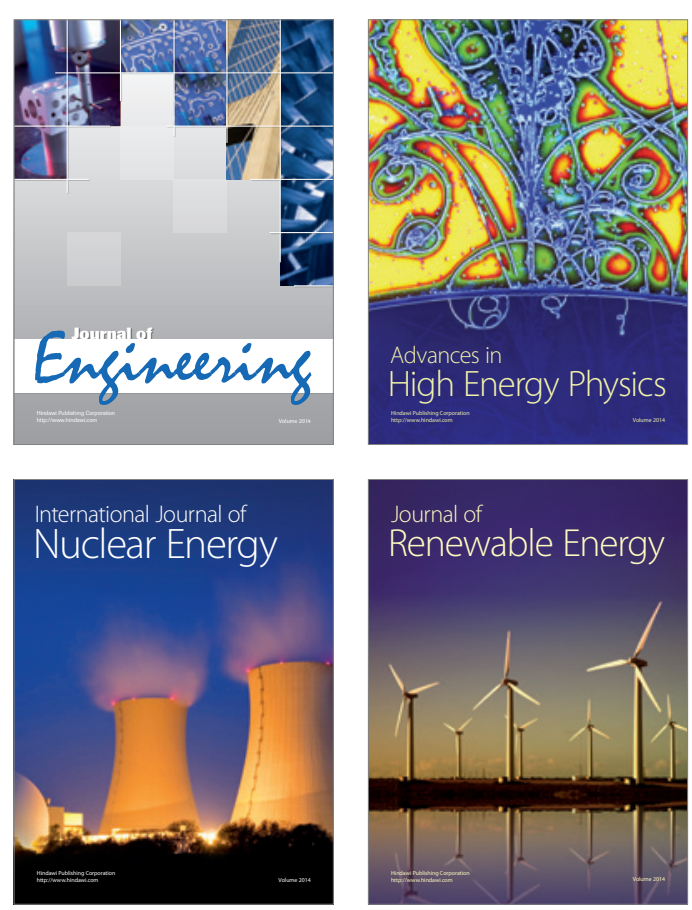

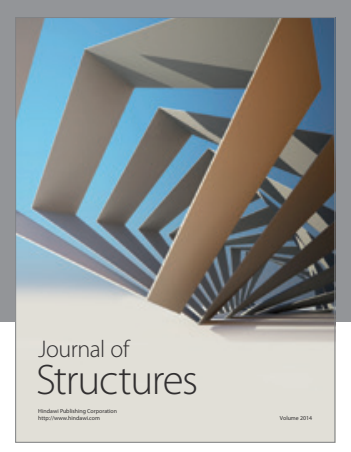

Rotating
Mechinery
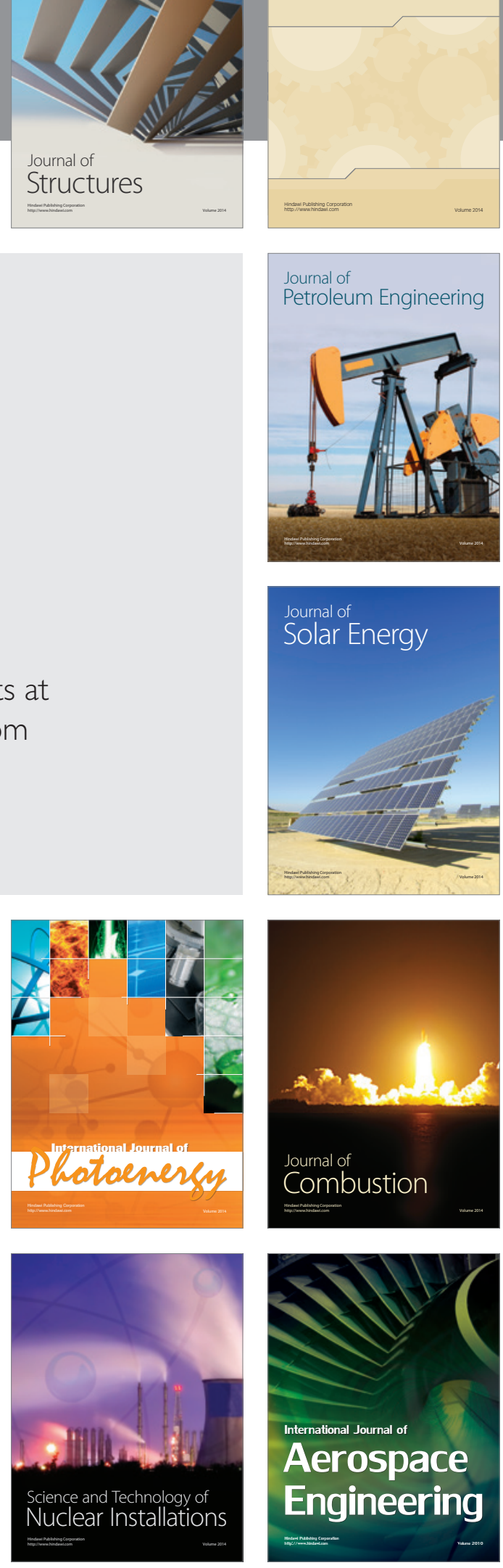